\title{
Prevotella marshii sp. nov. and Prevotella baroniae sp. nov., isolated from the human oral cavity
}

Correspondence

William G. Wade

william.wade@kcl.ac.uk

\author{
Julia Downes, ${ }^{1}$ lain Sutcliffe, ${ }^{2}$ Anne C. R. Tanner ${ }^{3}$ and William G. Wade ${ }^{1,3}$ \\ ${ }^{1}$ Infection Research Group, Dental Institute, King's College London, London SE1 9RT, UK \\ ${ }^{2}$ Division of Biomedical Sciences, School of Applied Sciences, Northumbria University, \\ Newcastle upon Tyne NE1 8ST, UK \\ ${ }^{3}$ Department of Molecular Genetics, The Forsyth Institute, Boston, MA 02115, USA
}

\begin{abstract}
Eleven strains of anaerobic Gram-negative bacilli isolated from the human oral cavity were subjected to a comprehensive range of phenotypic and genotypic tests and were found to comprise two homogeneous groups, designated E2 and E4. 16S rRNA gene sequence analysis revealed that members of both groups belonged to the genus Prevotella but were distinct from any species with validly published names. This distinction was confirmed by DNA-DNA hybridization and phenotypic tests. Two novel species are therefore proposed: Prevotella marshii sp. nov. (group E2) and Prevotella baroniae (group E4). Both species are saccharolytic; the end-products of fermentation for $P$. marshii are acetic, propionic and succinic acids, while $P$. baroniae produces acetic and succinic acids with minor amounts of isovaleric and isobutyric acids. The $\mathrm{G}+\mathrm{C}$ content of the DNA of the type strain of Prevotella marshii is $51 \mathrm{~mol} \%$ and that of Prevotella baroniae is $52 \mathrm{~mol} \%$. The type strain for $P$. marshii is $\mathrm{E} 9.34^{\top}$ (=DSM $16973^{\top}=$ CCUG $\left.50419^{\top}\right)$ and that for $P$. baroniae is E9.33 ${ }^{\top}\left(=\mathrm{DSM} 16972^{\top}=\right.$ CCUG $\left.50418^{\top}\right)$.
\end{abstract}

The genus Prevotella includes moderately saccharolytic, bilesensitive species formerly belonging to the genus Bacteroides (Shah \& Collins, 1990). Seventeen of the Prevotella species with validly published names are found in the oral cavity. The use of molecular methods, particularly $16 \mathrm{~S}$ rRNA gene sequence analysis, for the identification of oral bacterial isolates has revealed that a significant proportion of strains do not correspond to species with validly published names (Kroes et al., 1999; Munson et al., 2002, 2004). In this study, 11 strains of anaerobic Gram-negative bacilli, isolated from human oral infections and dental plaque in healthy subjects, provisionally identified as belonging to the genus Prevotella, were subjected to a range of phenotypic and genotypic tests.

Strains E9.33 ${ }^{\mathrm{T}}$, E9.34 ${ }^{\mathrm{T}}$ and W7346 were isolated from endodontic lesions, W5520 and W5712 were isolated from dental

Published online ahead of print on 1 March 2005 as DOI 10.1099/ ijs.0.63634-0.

Abbreviation: FAME, fatty acid methyl ester.

The GenBank/EMBL/DDBJ accession numbers for the 16S rRNA gene sequences of $P$. marshii E9.34 ${ }^{\top}, P$. baroniae $\mathrm{E} 9.33^{\top}, P$. loescheii NCTC $11321^{\top}$, P. oralis NCTC $11459^{\top}$, P. denticola ATCC $35308^{\top}$, $P$. melaninogenica ATCC $25845^{\top}$ and $P$. veroralis ATCC $33779^{\top}$ are AF481227, AY840553, AY836508, AY323522, AY323524, AY323525 and AY836507, respectively.

Transmission electron micrographs of $P$. baroniae E9.33 ${ }^{\top}$ and $P$. marshii E9.34 ${ }^{\top}$, an extended phylogenetic tree and details of FAME profiles are available as supplementary material in IJSEM Online. abscesses, W1833 was isolated from a pericoronitis lesion, D016C-10 and D031A-28 were isolated from supragingival plaque from individuals with periodontitis and strains D190A-02, D153G-12 and W6967 were isolated from subgingival plaque in periodontally healthy individuals. Strains D016C-10, D031A-28, D190A-02 and D153G-12 were obtained from the collection of W. E. C. Moore and L. V. Holdeman Moore, formerly of the Virginia Polytechnic Institute. Prevotella denticola ATCC $35308^{\mathrm{T}}$, Prevotella melaninogenica ATCC $25845^{\mathrm{T}}$, Prevotella veroralis ATCC $33779^{\mathrm{T}}$, Prevotella loescheii NCTC $11321^{\mathrm{T}}$, Prevotella oralis NCTC $11459^{\mathrm{T}}$, Prevotella shahii DSM $15611^{\mathrm{T}}$ and Prevotella buccae CCUG $15401^{\mathrm{T}}$ were obtained from the American Type Culture Collection (Manassas, VA, USA), the National Collection of Type Cultures, Central Public Health Laboratory (London, UK), the Deutsche Sammlung von Mikroorganismen und Zellkulturen (Braunschweig, Germany) or the Culture Collection of the University of Göteborg (Gothenburg, Sweden), respectively.

Strains were grown at $37^{\circ} \mathrm{C}$ on fastidious anaerobe agar (FAA; LabM), supplemented with $5 \%$ horse blood, under anaerobic conditions (in $\mathrm{N}_{2} / \mathrm{H}_{2} / \mathrm{CO}_{2}: 8010 ; 10$, by vol.) in an MAC anaerobic chamber (Don Whitley). Colonial morphologies were determined using a plate microscope after 5 days incubation. Cellular morphology was recorded after Gram staining of 2-day-old plate cultures. Hangingdrop preparations of $18 \mathrm{~h}$ cultures of peptone/yeast extract/ glucose (PYG; Holdeman et al., 1977) broth were examined 
under phase-contrast microscopy (Axioskop; Zeiss) for cellular motility. Transmission electron microscopy (H7600; Hitachi) was used to examine the cell-wall ultrastructure of strains $\mathrm{E} 9.34^{\mathrm{T}}$ and $\mathrm{E} 9.33^{\mathrm{T}}$ as described previously (Downes et al., 2003).

Fermentation tests were performed using pre-reduced, anaerobically sterilized sugars prepared in an anaerobic workstation (Holdeman et al., 1977). Other biochemical tests were performed using standard methods (Holdeman et al., 1977; Jousimies-Somer et al., 2002). Bacterial strains were grown in peptone/yeast extract (PY) broth (Holdeman et al., 1977) with and without glucose and short-chain volatile and non-volatile fatty acids were extracted by standard methods and analysed by GC (Holdeman et al., 1977). Enzyme profiles were generated with the Rapid ID $32 \mathrm{~A}$ anaerobe identification kit (bioMérieux), according to the manufacturer's instructions, using bacteria harvested from blood agar plates (blood agar base no. 2; LabM) supplemented with $5 \%$ horse blood, and performed in triplicate.

The cellular fatty acid composition was determined for 10 strains as described previously (Sutcliffe, 2000). In brief, fatty acids from lyophilized whole cells were derivatized to produce fatty acid methyl esters (FAMEs) by acid-catalysed methanolysis. FAMEs were recovered by hexane extraction and concentration under nitrogen, followed by GC analysis (Sutcliffe, 2000). FAMEs were identified by comparison with authentic FAME standards (Sigma).

The $\mathrm{G}+\mathrm{C}$ content of the DNA was estimated by using an HPLC method for E2 strains E9.34 ${ }^{\mathrm{T}}$ and D153G-12 and E4 strains $\mathrm{E} 9.33^{\mathrm{T}}$ and $\mathrm{W} 1833$ as described previously (Wade et al., 1999). A thermal denaturation method (Huß et al., 1983) was used to determine the DNA-DNA relatedness between strains.

DNA was isolated from the bacteria by using a standard method. Briefly, cells were suspended in TE buffer $(10 \mathrm{mM}$ Tris/HCl, $1 \mathrm{mM}$ EDTA, $\mathrm{pH} 8$; Sigma) and treated with lysozyme $\left(500 \mu \mathrm{g} \mathrm{ml}^{-1}\right)$ for $30 \mathrm{~min}$ at $37^{\circ} \mathrm{C}$ followed by proteinase $\mathrm{K}\left(500 \mu \mathrm{g} \mathrm{ml}^{-1}\right)$ and $20 \% \mathrm{~N}$-lauroyl-sarcosine (Sarkosyl; Sigma) (2\%) for $2 \mathrm{~h}$ at $37^{\circ} \mathrm{C}$. After two phenol/ chloroform extractions and one chloroform extraction, DNA was precipitated by the addition of two volumes of ethanol (stored at $-20{ }^{\circ} \mathrm{C}$ ) and washed in $70 \%$ ethanol. The 16S rRNA gene was amplified by a PCR with primers 27F and 1492R (Lane, 1991) and a Uno II Thermocycler (Biometra) using Ready to Go PCR beads (Pharmacia/ Amersham). PCR products were sequenced directly using a dye terminator cycle sequencing kit (CEQ DTCS; Beckman Coulter) and 60 ng template DNA, according to the manufacturer's instructions. Sequencing was performed using an automated sequencer (CEQ2000; Beckman Coulter) with primers 27f, 342r, 357f, 519r, 907r, 926f, 1100r, 1114f and 1492r (Lane, 1991); primers 1100r and 1114f had minor modifications (1100Ar, 5'-GGGTTGCGCTCGTTA3'; 1114ATf, 5'-ATAACGAGCGCAACCC-3'). Sequences were connected using the BioEdit program (Hall, 2004) and identified by BLAST interrogation of the GenBank database (Altschul et al., 1990). Related sequences were aligned by means of CLUSTAL X (Thompson et al., 1997). Further analysis was performed using the PHYLIP suite of programs (Felsenstein, 1993). Specifically, a distance matrix was constructed using the Jukes-Cantor algorithm with DNADIST, and NEIGHBOR was used to construct phylogenetic trees, which were viewed using TREEVIEW (Page, 1996).

The 11 strains studied were found to fall into two groups. Five strains, E9.34 ${ }^{\mathrm{T}}$, D190A-02, D153G-12, D016C-10 and D031A-28, designated group E2, had cells that were $0.4 \mu \mathrm{m}$ wide by $0.9-3 \mu \mathrm{m}$ long, with the occasional cell reaching $6 \mu \mathrm{m}$ in length, and occurred singly and in pairs. After 5 days incubation on FAA plates, E2 colonies were 1.8 $3.5 \mathrm{~mm}$ in diameter, circular and entire, convex, watery, opaque and grey to off-white/grey to greenish grey. Areas of heavier growth at the end of the streak lines on FAA were cream in colour. Viewed under a plate microscope, the colonies had a striated appearance with concentric rings of varying opacity and iridescent hues of pink, green and yellow.

The remaining six strains, designated group E4, consisted of coccoid and short bacilli, the majority of cells being $0 \cdot 6 \times 0 \cdot 6-2 \cdot 0 \mu \mathrm{m}$, with occasional cells ranging from 3 to $8 \mu \mathrm{m}$ in length. After 5 days incubation on FAA plates, E4 colonies were $1 \cdot 2-3.8 \mathrm{~mm}$ in diameter, circular, high convex and opaque with an off-white centre, which appeared matt in some strains and had a shiny grey periphery. Colony morphology varied from entire to undulate; this variation appeared to be strain-related but in some instances both forms were present in the same strain.

Transmission electron microscopic examination of ultrathin sections through the cells of E9.34 ${ }^{\mathrm{T}}$ (group E2) and E9.33 ${ }^{\mathrm{T}}$ (group E4) showed the presence of a typical Gramnegative cell wall composed of a thin peptidoglycan layer surrounded by an outer membrane (micrographs are available as Supplementary Fig. S1 in IJSEM Online).

Growth of all E2 strains in PY broth was good and produced a moderately turbid suspension $(3+$ on a scale of 0 to $4+)$ with a deposit of cells on standing. Growth was markedly enhanced by the addition of either glucose, fructose or maltose $(1 \%, \mathrm{w} / \mathrm{v}$, in each case), resulting in a heavily turbid suspension of $4+$. Strains were saccharolytic and fermented glucose and maltose strongly and fructose and mannose weakly and variably. Other sugars tested, listed in the species description, were not fermented. The major end-products of fermentation were acetic acid and succinic acid; minor to moderate amounts of propionic acid were also produced. Hydrolysis of gelatin was strongly positive, with pre-reduced, anaerobically sterilized gelatin tests not solidifying at $4{ }^{\circ} \mathrm{C}$. All E2 strains were positive for $\alpha$-glucosidase, alkaline phosphatase, leucyl glycine arylamidase, pyroglutamic acid arylamidase and alanine arylamidase in the Rapid ID 32A identification panel, while 
reactions for glutamyl glutamic acid arylamidase were weak and variable. All strains gave negative results in the remaining 23 tests, resulting in a Rapid ID 32A profile of $040044420 \%$. The G+C content of the DNA of strains E9.34 ${ }^{\mathrm{T}}$ and D153G-12 was $51 \mathrm{~mol} \%$.

Growth of E4 strains in PY broth was good $(3+)$ and produced a deposit of cells with a slightly turbid suspension $(1+)$ in PY broth and a clear supernatant in PYG broth on standing. Growth was somewhat enhanced by the addition of $1 \%(\mathrm{w} / \mathrm{v})$ fermentable carbohydrates. The major end-products of fermentation in PYG broth were acetic acid and succinic acid; isovaleric acid was a minor endproduct. In addition to these acids, minor amounts of isobutyric acid were produced in PY broth, and larger amounts of isovaleric acid were produced in PY broth than in PYG broth. All E4 strains were positive for $\alpha$ galactosidase, $\beta$-galactosidase, $\alpha$-glucosidase, $\beta$-glucosidase, $N$-acetyl- $\beta$-glucosaminidase, alkaline phosphatase, leucyl glycine arylamidase, alanine arylamidase and $\alpha$-fucosidase in the Rapid ID 32A identification panel, while reactions for mannose and raffinose fermentation and for glutamyl glutamic acid arylamidase were variable. All strains were negative for the remaining 17 tests, resulting in a Rapid ID 32A profile of $4511_{5}^{1 / l^{7}} 44022^{0} / 2$. The G+C content of the DNA of strains $\mathrm{E} 9.33^{\mathrm{T}}$ and W1833 was $52 \mathrm{~mol} \%$.

A phylogenetic tree showing the relationship between representative strains of groups E2 and E4 and other closely related species of the genus Prevotella is shown in Fig. 1. The 16S rRNA genes of the type strains of $P$. denticola, $P$. loescheii, $P$. melaninogenica, $P$. oralis and $P$. veroralis were sequenced and deposited with GenBank to improve the quality of the phylogenetic analysis, in view of the relatively

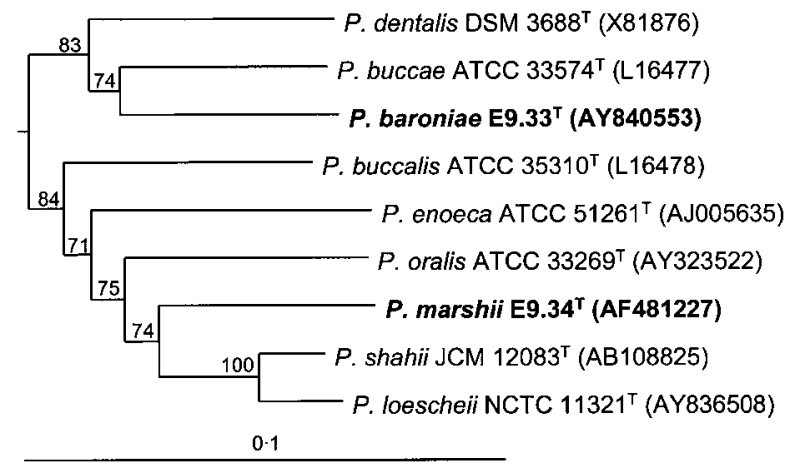

Fig. 1. Phylogenetic tree based on $16 \mathrm{~S}$ rRNA gene sequence comparisons over 1411 aligned bases showing the relationship between $P$. marshii, $P$. baroniae and related species. The tree was constructed using the neighbour-joining method following distance analysis of aligned sequences. Numbers represent bootstrap values for each branch, based on data for 100 trees. Accession numbers for $16 \mathrm{~S}$ rRNA sequences are given for each strain. Bar, $0 \cdot 1$ nucleotide substitutions per site. A fuller phylogenetic tree is available as Supplementary Fig. S2 in IJSEM Online. large number of ambiguous bases present in the sequences then available for these strains in the database. Group E2 strain E9.34 $4^{\mathrm{T}}$ was found to be most closely related to $P$. shahii (92.2\% 16S rRNA gene sequence identity over 1455 unambiguously aligned bases). In addition, the 16S rRNA gene was sequenced in E2 strains D190A-02, D153G-12, D016C-10 and D031A-28: over 1415 bases, each strain had $>99.7 \%$ sequence similarity to the other three strains and to strain $\mathrm{E} 9.34^{\mathrm{T}}$. E4 strain $\mathrm{E} 9.33^{\mathrm{T}}$ was most closely related to $P$. buccae ( $91.3 \%$ sequence identity over 1440 bases). E4 strains W1833, W6967 and W7346 each exhibited $>99 \cdot 5 \%$ $16 \mathrm{~S}$ rRNA gene sequence identity to the other two strains and to strain $\mathrm{E} 9.33^{\mathrm{T}}$ over 1404 bases.

The DNA-DNA relatedness between group E2 strains E9.34 ${ }^{\mathrm{T}}$ and D153G-12 was determined to be $80 \%$. The relatedness values between strain $\mathrm{E} 9.34^{\mathrm{T}}$ and $P$. loescheii NCTC $11321^{\mathrm{T}}$, P. oralis NCTC $11459^{\mathrm{T}}$ and P. shahii DSM $15611^{\mathrm{T}}$ were estimated to be 23,41 and $42 \%$, respectively. The DNA-DNA relatedness between group E4 strains E9.33 ${ }^{\mathrm{T}}$ and W1833 was $78 \%$ and that between each of these strains and P. buccae CCUG $15401^{\mathrm{T}}$ was 28 and $20 \%$, respectively.

Prevotella species are reported to synthesize both nonhydroxylated and 3-hydroxylated fatty acids (Shah \& Collins, 1990; Willems \& Collins, 1995). More than $90 \%$ of the FAMEs recovered from the strains studied were identifiable by GC as being non-hydroxylated (FAME data are available as Supplementary Table S1 in IJSEM Online). Of the non-hydroxylated fatty acids in Prevotella, methylbranched fatty acids (notably anteiso- $\mathrm{C}_{15: 0}$ ) are reported to predominate, along with $\mathrm{C}_{16: 0}$ (Logar et al., 2001; Moore et al., 1994; Sakamoto et al., 2004). Consistent with the assignment of E2 and E4 to the genus Prevotella, the main FAMEs detected in the present study were iso- $\mathrm{C}_{15: 0}$ and anteiso- $C_{15: 0}$, whilst $C_{16: 0}$ was abundant in strains from group E4. However, strains from group E4 were also distinguished by a high content of anteiso- $\mathrm{C}_{17: 0}$ FAMEs. Strains from group E2 were distinguished by a reduced content of $\mathrm{C}_{16: 0}$ and markedly increased $\mathrm{C}_{15: 0}$ content. Intriguingly, Sakamoto et al. (2004) identified significant quantities of unsaturated fatty acids in representative Prevotella species, including $P$. shahii and $P$. loescheii, which are phylogenetically closely related to group E2. However, unsaturated fatty acids have not been noted as major components by others using GC (Debelian et al., 1997; Logar et al., 2001; Moore et al., 1994) and were not observed in strains of groups E2 and E4 (see Supplementary Table S1). It is noted that mass spectrometry studies have also identified unsaturated fatty acids in Prevotella species, including mono-, di- and tri-unsaturated forms (Radcliffe et al., 2001; Tavana et al., 1998). It is clear that a comprehensive, integrated re-examination of the hydroxylated and non-hydroxylated fatty acid composition of members of the genus Prevotella is warranted.

The phenotypic and genotypic tests described here show that the strains tested fall into two groups that are distinct 
from any Prevotella species with validly published names. We propose the name Prevotella marshii sp. nov. for the strains in the E2 group and Prevotella baroniae sp. nov. for the E4 group, with E9.34 ${ }^{\mathrm{T}}\left(=\mathrm{DSM} 16973^{\mathrm{T}}=\right.$ CCUG $\left.50419^{\mathrm{T}}\right)$ and $\mathrm{E} 9.33^{\mathrm{T}}\left(=\right.$ DSM $16972^{\mathrm{T}}=$ CCUG $\left.50418^{\mathrm{T}}\right)$ as the respective type strains.

Phenotypic characteristics that distinguish $P$. marshii and P. baroniae from other Prevotella species are shown in Table 1. P. marshii is unusual in that it produces minor to moderate amounts of propionic acid as a by-product of fermentation. Although the characteristics shown will help in the identification of clinical isolates, unequivocal identification will not be possible in all cases. 16S rRNA gene sequence analysis is recommended for the identification of clinical isolates in this genus, not least because the many additional unnamed Prevotella taxa will be recognized by this method.

\section{Description of Prevotella marshii sp. nov.}

Prevotella marshii (mar'shi.i. N.L. gen. n. marshii of Marsh, named in honour of British microbiologist Philip Marsh, for his contributions to oral microbiology).

The description is based on five strains isolated from the human oral cavity. Cells are obligately anaerobic, nonmotile, Gram-negative bacilli $(0 \cdot 4 \times 0 \cdot 9-3 \mu \mathrm{m})$ occurring singly and in pairs with an occasional elongated cell up to $6 \mu \mathrm{m}$ long. After 5 days incubation on FAA plates, colonies are $1.8-3.5 \mathrm{~mm}$ in diameter, circular and entire, convex, watery, opaque and grey to off-white/grey to greenish grey. Areas of heavier growth at the end of the streak lines on FAA are cream in colour. Viewed under a plate microscope the colonies have a striated appearance with concentric rings of varying opacity and iridescent hues of pink, green and yellow. Growth in broth media produces moderate turbidity that is markedly enhanced by the addition of glucose, fructose or maltose. Cells are saccharolytic and ferment glucose and maltose strongly and fructose and mannose weakly and variably. Arabinose, cellobiose, lactose, mannitol, melezitose, melibiose, raffinose, rhamnose, ribose, salicin, sorbitol, sucrose and trehalose are not fermented. Major amounts of acetic acid and succinic acid and moderate amounts of propionic acid are produced as end-products of metabolism in PYG broth. Gelatin is hydrolysed; aesculin, arginine and urea are not hydrolysed. Indole and catalase are not produced and nitrate is not reduced. There is no growth in $20 \%$ bile. The Rapid ID 32A profile is $040044420 \%$. The fatty acid profile predominantly comprises anteiso- $\mathrm{C}_{15: 0}$, iso- $\mathrm{C}_{15: 0}, \mathrm{C}_{15: 0}$ and iso$\mathrm{C}_{14: 0}$. The $\mathrm{G}+\mathrm{C}$ content of the DNA of the type strain is $51 \mathrm{~mol} \%$.

Isolated from the human oral cavity in subjects with endodontic and periodontal infections and from subgingival dental plaque in healthy subjects. The type strain is E9.34 $4^{\mathrm{T}}\left(=\right.$ DSM $16973^{\mathrm{T}}=$ CCUG $\left.50419^{\mathrm{T}}\right)$.

\section{Description of Prevotella baroniae sp. nov.}

Prevotella baroniae (bar'on.i.ae. N.L. gen. n. baroniae of Baron, named in honour of Ellen Jo Baron, the American microbiologist, for her contributions to clinical microbiology).

The description is based on six strains isolated from the human oral cavity. Cells are obligately anaerobic, non-motile, Gram-negative coccoid and short bacilli $(0 \cdot 6 \mu \mathrm{m} \times 0 \cdot 6-2 \cdot 0 \mu \mathrm{m})$ with occasional cells ranging from 3 to $8 \mu \mathrm{m}$ long. After 5 days incubation on FAA plates, colonies are $1 \cdot 2-3 \cdot 8 \mathrm{~mm}$ in diameter, circular, high convex and opaque with a shiny grey periphery and an off-white

Table 1. Characteristics that distinguish $P$. baroniae sp. nov. and $P$. marshii sp. nov. from related Prevotella species

1, P. buccae; 2, P. dentalis; 3, P. oris; 4, P. salivae; 5, P. buccalis; 6, P. loescheii; 7, P. oralis; 8, P. veroralis; 9, P. baroniae sp. nov.; 10, P. denticola; 11, P. enoeca; 12, P. melaninogenica; 13, P. shahii; 14, P. oulorum; 15, P. intermedia; 16, P. nigrescens; 17, P. pallens; 18, P. tannerae; 19, P. marshii sp. nov. +, Positive; -, negative; V, variable; W, weak.

\begin{tabular}{|c|c|c|c|c|c|c|c|c|c|c|c|c|c|c|c|c|c|c|c|}
\hline Characteristic & 1 & 2 & 3 & 4 & 5 & 6 & 7 & 8 & 9 & 10 & 11 & 12 & 13 & 14 & 15 & 16 & 17 & 18 & 19 \\
\hline Production of pigment on blood agar & - & - & - & - & - & + & - & - & - & + & - & + & + & - & + & + & + & + & - \\
\hline \multicolumn{20}{|l|}{ Fermentation of: } \\
\hline Arabinose & + & + & + & + & - & - & - & - & - & - & - & - & - & - & - & - & - & - & - \\
\hline Cellobiose & + & + & + & + & + & + & + & + & + & - & - & - & - & - & - & - & - & - & - \\
\hline Lactose & + & + & + & + & + & + & + & + & + & + & + & + & + & + & - & - & - & $\mathrm{V}$ & - \\
\hline Mannose & + & + & + & + & + & + & + & + & + & + & + & + & + & + & $\mathrm{V}$ & + & - & $\mathrm{V}$ & $\mathrm{V}$ \\
\hline Raffinose & + & + & + & + & + & + & + & + & + & + & - & + & + & + & $\mathrm{V}$ & + & + & $\mathrm{V}$ & - \\
\hline Salicin & + & - & + & + & - & - & + & - & + & - & - & - & - & - & - & - & - & - & - \\
\hline Sucrose & + & $\mathrm{W}$ & + & + & + & + & + & + & + & + & - & + & + & + & + & + & + & $\mathrm{V}$ & - \\
\hline Xylose & + & - & + & + & - & - & - & - & - & - & - & - & - & - & - & - & - & - & - \\
\hline Indole production & - & - & - & - & - & - & - & - & - & - & - & - & - & - & + & + & + & - & - \\
\hline Aesculin hydrolysis & + & + & + & + & + & + & + & + & + & + & $\mathrm{V}$ & $\mathrm{V}$ & - & + & - & - & - & - & - \\
\hline Gelatin liquefaction & + & - & $\mathrm{V}$ & - & - & + & $\mathrm{V}$ & $\mathrm{V}$ & $\mathrm{W}$ & + & + & + & + & - & + & + & + & + & + \\
\hline
\end{tabular}


centre, which appears matt in some strains. Colony morphology varies from entire to undulate. Growth in PY broth is good and is somewhat enhanced by the addition of $1 \%(\mathrm{w} / \mathrm{v})$ fermentable carbohydrates. Cells are saccharolytic and ferment cellobiose, fructose, glucose, lactose, maltose, mannose, melibiose, raffinose, salicin and sucrose. Arabinose, mannitol, melezitose, rhamnose, ribose, sorbitol and trehalose are not fermented. End-products of fermentation in PYG broth are major acetic and succinic acids and minor isovaleric acid. Minor amounts of isobutyric acid are also produced in PY broth. Aesculin is hydrolysed, gelatin is weakly hydrolysed and arginine and urea are not hydrolysed. Indole and catalase are not produced and nitrate is not reduced. There is no growth in $20 \%$ bile. The Rapid ID 32A profile is $451{ }_{5} / /^{7} 44022 \%$. The non-hydroxylated fatty acid profile predominantly comprises iso- $\mathrm{C}_{15: 0}$, anteiso- $\mathrm{C}_{15: 0}$, $\mathrm{C}_{16: 0}$ and anteiso- $\mathrm{C}_{17: 0}$. The $\mathrm{G}+\mathrm{C}$ content of the DNA of the type strain is $52 \mathrm{~mol} \%$.

Isolated from the human oral cavity in patients with endodontic and periodontal infections or dentoalveolar abscesses and from the dental plaque of healthy subjects. The type strain is $\mathrm{E} 9.33^{\mathrm{T}}\left(=\mathrm{DSM} 16972^{\mathrm{T}}=\right.$ CCUG $\left.50418^{\mathrm{T}}\right)$.

\section{Acknowledgements}

This work was supported by grants from the Guy's and St Thomas' Charitable Foundation (ref. R020725) and National Institute of Dental and Craniofacial Research (ref. DE 09513).

\section{References}

Altschul, S. F., Gish, W., Miller, W., Myers, E. W. \& Lipman, D. J. (1990). Basic local alignment search tool. J Mol Biol 215, 403-410.

Debelian, G. J., Olsen, I. \& Tronstad, L. (1997). Distinction of Prevotella intermedia and Prevotella nigrescens from endodontic bacteremia through their fatty acid contents. Anaerobe 3, 61-68.

Downes, J., Munson, M. \& Wade, W. G. (2003). Dialister invisus sp. nov., isolated from the human oral cavity. Int J Syst Evol Microbiol 53, 1937-1940.

Felsenstein, J. (1993). PHYLIP (phylogeny inference package), version 3.5c. Distributed by the author. Department of Genome Sciences, University of Washington, Seattle, USA.

Hall, T. (2004). BioEdit. Biological sequence alignment editor for Win95/98/NT/2K/XP. http://www.mbio.ncsu.edu/BioEdit/bioedit. html

Holdeman, L. V. H., Cato, E. P. \& Moore, W. E. C. (1977). Anaerobe Laboratory Manual, 4th edn. Blacksburg, VA: Virginia Polytechnic Institute and State University.

Huß, V. A. R., Festl, H. \& Schleifer, K.-H. (1983). Studies on the spectrophotometric determination of DNA hybridisation from renaturation rates. Syst Appl Microbiol 4, 184-192.

Jousimies-Somer, H., Summanen, P., Citron, D. M., Baron, E. J., Wexler, H. M. \& Finegold, S. M. (2002). Wadsworth Anaerobic Bacteriology Manual, 6th edn. Belmont, CA: Star Publishing.
Kroes, I., Lepp, P. W. \& Relman, D. A. (1999). Bacterial diversity within the human subgingival crevice. Proc Natl Acad Sci U S A 96, 14547-14552.

Lane, D. J. (1991). 16S/23S rRNA sequencing. In Nucleic Acid Techniques in Bacterial Systematics, pp. 115-175. Edited by E. Stackebrandt \& M. Goodfellow. Chichester, UK: Wiley.

Logar, R. M., Zorec, M. \& Kopecny, J. (2001). Reliable identification of Prevotella and Butyrivibrio spp. from rumen by fatty acid methyl ester profiles. Folia Microbiol 46, 57-59.

Moore, L. V., Bourne, D. M. \& Moore, W. E. (1994). Comparative distribution and taxonomic value of cellular fatty acids in thirtythree genera of anaerobic Gram-negative bacilli. Int J Syst Bacteriol 44, 338-347.

Munson, M. A., Pitt-Ford, T., Chong, B., Weightman, A. \& Wade, W. G. (2002). Molecular and cultural analysis of the microflora associated with endodontic infections. J Dent Res 81, 761-766.

Munson, M. A., Banerjee, A., Watson, T. F. \& Wade, W. G. (2004). Molecular analysis of the microflora associated with dental caries. J Clin Microbiol 42, 3023-3029.

Page, R. D. M. (1996). TREEVIEW: an application to display phylogenetic trees on personal computers. Comput Appl Biosci 12, 357-358.

Radcliffe, C. E., Korachi, M. A. O., Könönen, E., Boote, V. \& Drucker, D. B. (2001). Phospholipid analogue distribution of Prevotella pallens and related species analysed by fast atom bombardment mass spectrometry. Anaerobe 7, 87-91.

Sakamoto, M., Suzuki, M., Huang, Y., Umeda, M., Ishikawa, I. \& Benno, Y. (2004). Prevotella shahii sp. nov. and Prevotella salivae sp. nov., isolated from the human oral cavity. Int J Syst Evol Microbiol 54, 877-883.

Shah, H. N. \& Collins, D. M. (1990). Prevotella, a new genus to include Bacteroides melaninogenicus and related species formerly classified in the genus Bacteroides. Int J Syst Bacteriol 40, 205-208.

Sutcliffe, I. C. (2000). Characterisation of a lipomannan lipoglycan from the mycolic acid containing actinomycete Dietzia maris. Antonie van Leeuwenhoek 78, 195-201.

Tavana, A. M., Drucker, D. B., Hull, P. S. \& Boote, V. (1998). Phospholipid molecular species distribution of oral Prevotella corporis clinical isolates. FEMS Immunol Med Microbiol 21, 57-64.

Thompson, J. D., Gibson, T. J., Plewniak, F., Jeanmougin, F. \& Higgins, D. G. (1997). The CLUSTAL_X windows interface: flexible strategies for multiple sequence alignment aided by quality analysis tools. Nucleic Acids Res 25, 4876-4882.

Wade, W. G., Downes, J., Dymock, D., Hiom, S. J., Weightman, A. J., Dewhirst, F. E., Paster, B. J., Tzellas, N. \& Coleman, B. (1999). The family Coriobacteriaceae: reclassification of Eubacterium exiguum (Poco et al. 1996) and Peptostreptococcus heliotrinreducens (Lanigan 1976) as Slackia exigua gen. nov., comb. nov. and Slackia heliotrinireducens gen. nov., comb. nov., and Eubacterium lentum (Prevot 1938) as Eggerthella lenta gen. nov., comb. nov. Int J Syst Bacteriol 49, 595-600.

Willems, A. \& Collins, M. D. (1995). 16S rRNA gene similarities indicate that Hallella seregens (Moore and Moore) and Mitsuokella dentalis (Haapsalo et al.) are genealogically highly related and are members of the genus Prevotella: emended description of the genus Prevotella (Shah and Collins) and description of Prevotella dentalis comb. nov. Int J Syst Bacteriol 45, 832-836. 